\title{
Scenario analysis of perspective change to support climate adaptation: lessons from a pilot study on Dutch river management
}

\author{
P. Valkering $\cdot$ R. van der Brugge $\cdot$ A. Offermans $\cdot$ \\ N. Rijkens-Klomp
}

Received: 11 February 2010/Accepted: 15 August 2010/Published online: 2 September 2010

(C) The Author(s) 2010. This article is published with open access at Springerlink.com

\begin{abstract}
Climate adaptation is a complex task surrounded by uncertainty. To support climate adaptation policies, a new scenario approach is pursued to explore possible discontinuous future developments of societal perspectives on climate adaptation issues. The scenario approach was tested for a case study on Dutch river management. In a series of scenario development workshops, a select group of stakeholders explored the perspectives on the management of the River Meuse in the past, present, and future. The process was supported by an analytical perspectives mapping tool to illustrate and analyze the development of perspectives over time. The process and analytical tools contributed to insight into the drivers of perspective change for the case study at hand. Moreover, the stakeholders highlighted the potential of the approach for water management policy for creating awareness about the plurality of perspectives and the dynamics of perspective change, monitoring perspectives and perspective change as part of a flexible policy approach, and anticipating on the occurrence of shock events. Further work is required to better represent the social dynamics of perspectives change, to better empirically ground the perspective change model, and to apply integrated water
\end{abstract}

\footnotetext{
P. Valkering $(\bowtie) \cdot$ A. Offermans $\cdot$ N. Rijkens-Klomp International Centre for Integrated Assessment and Sustainable Development (ICIS), Maastricht University, P.O. Box 616, 6200 MD Maastricht, The Netherlands e-mail: p.valkering@maastrichtuniversity.nl

R. van der Brugge

Deltares, Daltonlaan 400, 3584 BK Utrecht, The Netherlands

N. Rijkens-Klomp

Pantopicon, Cogels Osylei 36, 2600 Antwerp, Belgium
}

models in the scenario development process to assess water-society interactions.

Keywords Scenario analysis - River management . Perspectives mapping tool - Stakeholder participation . Climate adaptation

\section{Introduction}

Global climate is changing. Increasing global temperature, and the associated change of regional weather patterns, is expected to cause significant impacts for water systems, ecosystems, food security, coastal management, and health (IPCC 2007). The current challenge is to design and implement both effective mitigation strategies to avoid "dangerous climate change", and adaptation strategies to adapt to the unavoidable climate change (Hulme et al. 2009; Richardson et al. 2009). This paper focuses on the issue of climate adaptation in Dutch river management. Here, adaptation is necessary to cope with expected increases in both flood risk and drought problems, as a combined result of climate change, urbanization, and increasing water demand (Valkering 2009).

Climate adaptation, however, is not an easy task, among others because it is surrounded by uncertainty. One may consider uncertainty in the natural environment (e.g. the magnitude of regional climate change and its impacts on regional water systems) and in the socioeconomic context (economic and demographic development), to name but a few. A specific uncertainty considered in this paper is the societal response to climate change. Will people continue to regard climate change as a major problem, or will the concern fade? Will people put the climate adaptation issue in the hands of governments, or will people take their own 
responsibility? How will the dominant societal attitude toward various river management approaches-such as dike-building, natural river restoration, and flood adaptation-develop? In other words, how might the societal perspective $^{1}$ on climate adaptation co-evolve with the development of climate, the river system, and the broader socioeconomic context, and what are the consequences for climate adaptation policy?

Uncertainty can be explored through scenario analysis. A variety of scenario analysis approaches currently exist, including quantitative and qualitative approaches, forecasting and back-casting studies, descriptive and normative scenario types, and combinations of those, each with their own strengths and weaknesses (see Bishop et al. 2007; Van Notten 2005; Swart et al. 2004 for overviews). Current scenario studies, however, are subject to two (closely related) limitations. First, they tend to reflect only implicitly the development of societal perspectives on the issue under concern. They tend to focus on 'conventional' uncertainties-e.g. in climate, demography, land use, and economy - and much less on the development of problem perceptions and 'new ways of thinking' emerging in a society. Second, current scenarios tend to reflect rather linear development paths, in which context developments, lifestyles, and policies develop in continuous trends. Reality, however, tends to exhibit strongly discontinuous developments, notably as a society responds to events and perceived developments. Including those types of dynamics in scenarios is considered a main challenge in scenario development practice (Van Asselt et al. 2005; Van Notten 2005).

This paper seeks to address this challenge. It aims to develop a novel way to coherently explore the dynamics of societal perspective change in scenario analysis for a climate adaptation issue. This approach builds upon so-called perspective-based scenario analysis. This method was developed for the integrated modeling of global change (De Vries 2001; Hoekstra 1998; Rotmans and de Vries 1997; Van Asselt and Rotmans 1996). It has also been applied to develop long-term scenarios for the Rhine and Meuse in the Netherlands (Middelkoop et al. 2004; Van Asselt et al. 2001). In perspective-based scenario analysis, one generally adopts the typology of perspectives of Cultural Theory (Thompson et al. 1990) to map out different interpretations of uncertainties and management preferences as part of distinct, stereotype cultural worldviews, and management styles. Different combinations of worldviews and management styles then generate different future images, which are further analyzed.

\footnotetext{
${ }^{1}$ A formal definition of the term 'perspective' is given in "Perspective-based scenario analysis".
}

Our scenario approach aims to extend this method by describing the 'real-world' societal perspectives in the scenarios (rather than only the stereotypical ones), and by including the dynamics that may eventually lead to perspective change. This 'extended perspectives approach' was developed and tested in the project 'Perspectives in Integrated Water Management' (Valkering et al. 2008) that focussed on the management of the River Meuse in the Dutch Province of Limburg. The backbone of this project was formed by a participatory scenario development processaddressing societal perspectives in the past, present and future-supported by an analytical perspectives mapping tool. The project is best described as a pilot study, an 'experiment' to explore a novel method for participatory scenario development, and to assess its potential for representing societal responses in the form of perspective change, and for supporting water management and climate adaptation policy. The main research questions addressed in this paper therefore are the following:

- How to systematically include societal perspective dynamics in scenario analysis?

- To what extent does the extended perspectives approach provide insights into the drivers of perspective change?

- What is the potential contribution of the extended perspectives approach for supporting water management policy and societal learning?

"Towards scenario analysis of perspective change" describes our point of departure (perspective-based scenario analysis) and the analytical perspectives mapping tool. "Case study of the River Meuse" presents the results of the case study of the Meuse in Limburg. "Discussion and outlook" discusses main lessons learned (on the basis of the questions above) and sketches avenues for further development of the scenario methodology. "Conclusion" presents our main conclusions.

\section{Towards scenario analysis of perspective change}

Scenario analysis

Scenario analysis is a means for structured thinking about the future (Rothman 2006). In this paper, scenarios are defined as "coherent descriptions of alternative hypothetical futures that reflect different perspectives on past, present and future developments, which can serve as a basis for action" (Van Notten 2005). This definition reflects that scenarios are not predictions, but rather explorations of hypothetical futures, that they describe both an end-state as well as the trajectories leading to that state, and that the description should be coherent, meaning that 


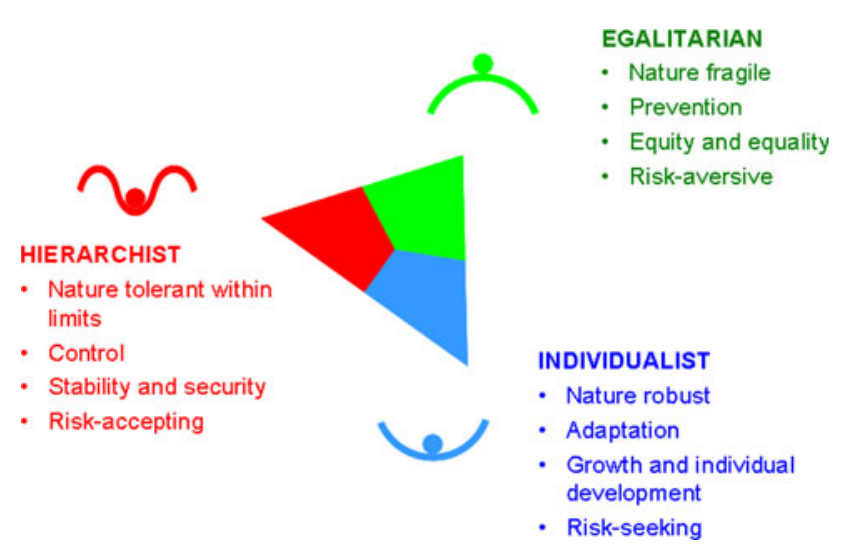

Fig. 1 Main characteristics of the stereotypical perspectives of Cultural Theory. Adapted from Van Asselt (2000)

causal relations are reflected in a valid way. The scenario descriptions can be qualitative (narrative) and/or quantitative, often containing a mix of both. Scenario analysis may serve a number of goals: to illuminate potential future problems, to explore policy alternatives in the face of uncertainty, to share understanding and concerns, to uncover and test assumptions, and to help identify choices and make decisions (Rothman 2006).

Perspective-based scenario analysis

Perspective-based scenario analysis is based upon the pluralistic approach of Van Asselt (2000). Pluralism implies that different perspectives on uncertainty are legitimate. A perspective is thereby defined as "a coherent and consistent description of the perceptual screen through which (groups of) people interpret or make sense of the world and its social dimensions, and which guide them in acting" (Van Asselt 2000). It includes the fundamental values, beliefs, and norms on the basis of which one interprets uncertainty and decides upon actions to take. A perspective thus contains a 'worldview' (how the world is perceived) and a 'management style' (how they act upon it). In perspective-based scenario analysis, one generally draws from the group-grid typology of Cultural Theory (Thompson et al. 1990) to delineate a number of stereotypical perspectives. These map out the extreme (but still legitimate) ways of interpreting uncertainty. Out of the five different 'ways of life', three are generally used: the hierarchist, the egalitarian, and the individualist ${ }^{2}$ (see Fig. 1).

Each stereotypical perspective holds a fundamentally different view on water management (see Hoekstra 1998; Valkering et al. 2008; Van Asselt et al. 2001; Verweij and

\footnotetext{
2 The two remaining perspectives 'fatalist' and 'hermit' are generally omitted in policy studies, since in both perspectives the concept of active policy is rejected.
}

Thompson 2006). In perspective-based scenario analysis, these views are translated into consistent interpretations of uncertainty (as part of the world view) and a corresponding choice of management style. Different combinations of world views and management styles then generate different futures that portray diverging developments of the water system and its broader context. By testing the management styles under different world views, the robustness of the management styles can be assessed (the so-called utopiadystopia analysis). The perspective-based scenario study for the Dutch Rhine and Meuse, for example, showed that the hierarchist management style — often followed in Dutch water management-focussed on 'win-win' solutions, may lead to loose-loose situations if climate change turns out more severe than expected from the hierarchist world view (Middelkoop et al. 2004; Van Asselt et al. 2001).

A key characteristic of perspective-based scenario analysis is that the set of scenario archetypes (i.e. the stereotypical perspectives) is imposed top-down on the scenario process, rather then allowing archetypes to emerge, e.g. by working with scenario-axis (Van 't Klooster and Van Asselt 2006), or through the clustering of storylines (Van Asselt et al. 2005). Although this procedure can be considered as a constraint, it is considered a strength at the same time. First, it allows for a consistent classification of a broad range of uncertainties, rather than focusing on a limited number of salient drivers. Second, it ensures that a diverse range of perspectives is included in the scenario study, whereas using other approaches, different scenarios may reflect similar perspectives (Van Asselt et al. 2001).

\section{Points of improvement}

Despite the added value of perspective-based scenario analysis 'as-it-is' for the assessment of water management strategies, we formulate two main points of improvement (see also Van Asselt et al. 2001). First, the use of stereotypical perspectives runs the risk of ignoring the 'real' perspectives stakeholders may have. It, in principle, ignores what actual stakeholders define as problems, and how they perceive future developments and possible management solutions, given their underlying beliefs and values. One simply assumes that, in a society, a stereotypical world view and management style form either a perfect match (utopia), or a perfect mismatch (dystopia). In reality, other shades will exist, for example that the management style is only partly in correspondence with the dominant societal world view, or that there are multiple competing societal worldviews that each evaluate the management style in different ways. As such it is not yet fully equipped to provide a nuanced assessment of societal support for the various management styles (see also Offermans et al. 2009).

Second, current perspective-based scenario analysis does not take into account trajectories in which management 
style and world view change over time. Retrospective analysis of Dutch water management, however, indicates that trend breaks are likely to occur, especially related to extreme events such as flooding. Van der Brugge et al. (2005), for example, shows that the shift in Dutch water management over the past decades from 'fighting water' to 'accommodating water' reflects a fundamental perspective change corresponding to a shift from a hierarchical to a more egalitarian management style. The current method is not yet capable of exploring such type of non-linear dynamics. It therefore fails to describe adaptation pathways (rather than 'static' management styles), which will most probably unfold in a highly dynamic world, in which societal world views will be continuously subject to change. Hence, there is a need for including the discontinuous development of societal perspectives in the scenario analysis process (see also Haasnoot et al. 2009).

Analytical framework for describing and analyzing societal perspective dynamics

Current scenario practice does not ignore societal perspectives and perspective change. In participatory backcasting (Kok et al. 2006; Van de Kerkhof et al. 2002), for example, factors related to societal perspective change (like 'public acceptance' or 'cultural change') are often implicitly included in back-casting trajectories toward an end-state. In the European scenarios of the VISIONS project (Van Asselt et al. 2005), perspective dynamics comes to the fore both in the main scenario narratives (e.g. ongoing individualization in the 'Big is Beautiful' scenario) as well in the various bifurcations ${ }^{3}$ to those scenarios (e.g. 'what if businesses become socially responsible?'). In the TRANSCE approach of Sondeijker (2009), perspective change is explicitly considered in the scenario analysis of structural societal change. Furthermore, Van Notten (2005) experimented with a perspective-based back-casting technique. None of the above approaches, however, provide a systematic approach for describing and analyzing perspective dynamics, and therefore provide limited insight into the dynamics of such perspective change.

Providing such a systematic approach poses an obvious challenge. In any society, perspectives may vary from individual to individual, across scale levels (individual, family, community, region, country), and actor groups (water managers, farmers, residents, boaters, conservationists). Perspective change, then, is a highly complex process involving various events, developments, and actor interactions. Given this complexity, we derived three basic

\footnotetext{
3 Bifurcations describe scenario variants that may occur if circumstances at key points differ; events or developments that violate one's assumptions about how systems behave.
}

principles as starting points to describe and analyze societal perspectives and perspective change:

- Perspectives are heterogeneous: In reality, the perspective of any individual or other social actor is in principle never of the stereotypical 'pure' type. It always contains elements of various stereotypical perspectives. As such, a perspective can be decomposed to a set of salient beliefs (in our case regarding the management of the River Meuse), which should be assessed individually in order to properly reflect ones perspective. To this end, societal perspectives are operationalized on the so-called perspectives map, see "The perspectives mapping tool".

- Perspective change is driven by surprise: Surprises (Thompson et al. 1990) are defined as events or developments that challenge one's perspective. ${ }^{4}$ Conversely, one may speak of 'confirmations' as events and developments that confirm one's perspective. It is assumed that surprises and a lack of confirmations may drive perspective change. However, perspectives are considered to be deeply rooted and therefore resistant to change (Thompson et al. 1990). Therefore, we hypothesize that an accumulation of surprises and a persistent lack of confirmations are necessary to induce perspective change.

- Perspective change emerges from a competition between a dominant perspective and undercurrents: Following transition theory (Rotmans 2005; Van der Brugge 2009), one may discriminate between the 'dominant perspective' and the less dominant perspectives, called 'undercurrents'. The dominant perspective is hereby defined as the perspective that receives the largest societal support. An undercurrent is seen as a distinguishable 'social movement'-possibly linked to specific individuals, organizations, and networkswhich clearly advocates a different perspective then the dominant one. Undercurrents may exist long while hardly being noticed; however, appropriate surprises and confirmations may form the breeding ground for undercurrents to grow and eventually replace the dominant perspective.

Summarizing, our view of societal perspective change is one where multiple societal perspectives co-evolve. This co-evolution is visualized on the perspectives triangle of Fig. 2, which shows the position of the perspectives,

\footnotetext{
${ }^{4}$ This definition of surprise is in line with other definitions in the scenario literature, e.g. as 'unexpected discrete events, 'discontinuities in long-term trends', and 'the sudden emergence of new information'. The current definition highlights that a surprise is never surprising in itself, but only in relation to the perception of the observer (see Van Notten 2005).
} 
Fig. 2 Societal perspective change on river management is seen as a co-evolution of multiple perspectives including a dominant perspective and possibly multiple undercurrents. The perspectives are characterized by their 'position' (specified on the perspectives map) and 'size' (representing their societal support). The perspectives shown reflect the dominant water management perspective and hypothetical undercurrents of the present, see "Perspectives in the present"

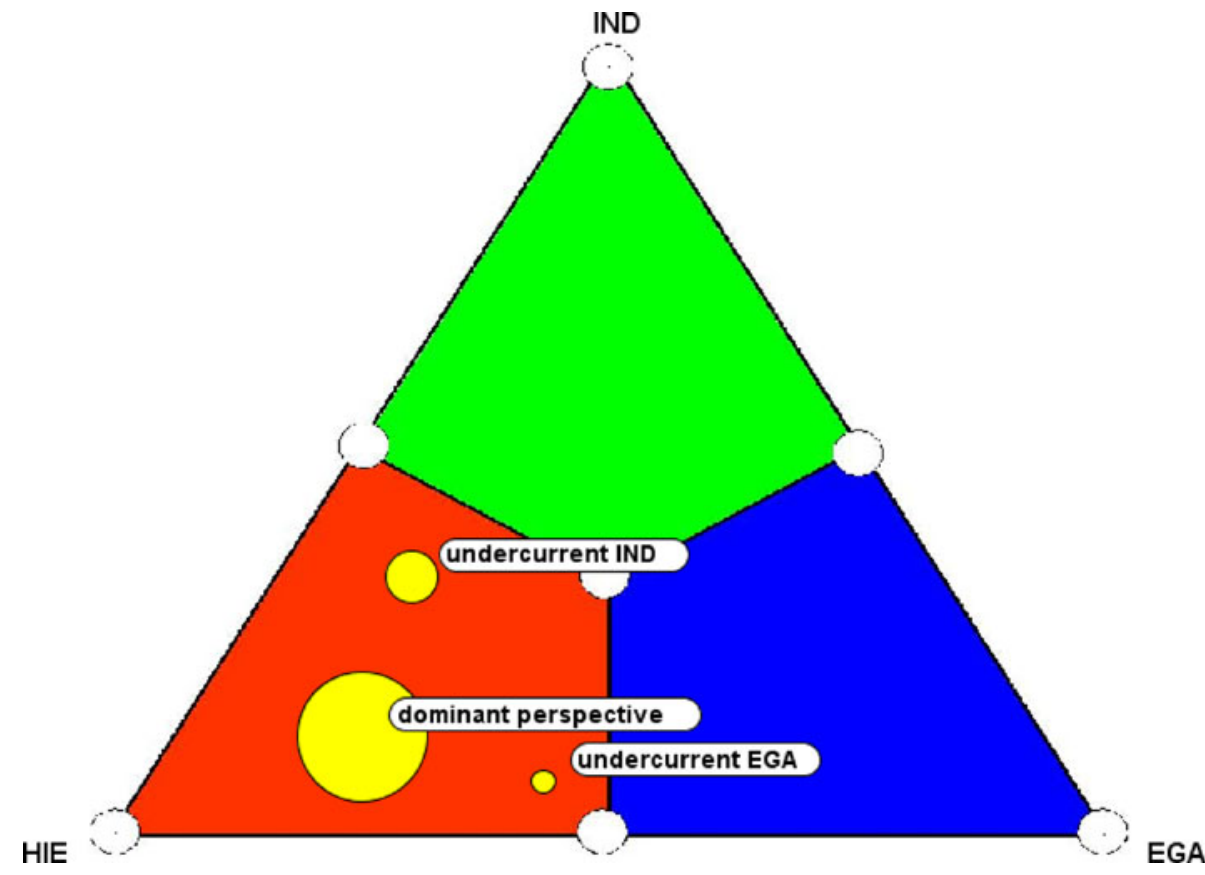

calculated from the perspectives map. ${ }^{5}$ The co-evolution involves both changing positions and changing societal support, which is visualized as the circle's size. Changes in societal perspective are reflected through a change of the position of the dominant perspective on the perspectives map, or through a change in the societal support from the dominant perspective to an undercurrent competitor. These dynamics are driven by surprising and confirming events and developments in the water system, the societal system, and its larger context.

\section{The perspectives mapping tool}

The analytical framework above translates to a concrete tool to support the scenario analysis process: the so-called perspectives mapping tool (see also Offermans et al. 2009). The perspectives map (see Fig. 3) consists of a set of salient beliefs pertaining to world view and management style. For each belief, the hierarchist, individualist, and egalitarian positions are given. Regarding the management of flood safety, for example, the hierarchist believes in the principle of flood prevention, the egalitarian believes flood-prone areas should be abandoned, while the individualist would favor innovative solutions for flood resistant building in flood-prone areas. The perspective of any societal actor is then mapped by deciding for each one of the salient beliefs whether it

\footnotetext{
5 The position on the perspectives triangle reflects the average position on the perspectives map specified in so-called barycentric coordinates.
}

supports the hierarchist, egalitarian, or individualist view (or perhaps multiple or none of those). The perspectives map was implemented in a simple computer tool. The average position on the perspectives map is then visualized in the perspectives triangle of Fig. 2.

In the case study of the River Meuse (described in the next section), the perspectives map was applied in two complementary ways. First, it was used as an analytical tool for ex-post analysis of perspective dynamics elicited from the stakeholder workshops. It was used, for example, to interpret and analyze historical perspective changes recorded during a stakeholder workshop. Second, it was used as a participatory tool operated during the workshops. For example, workshop participants applied the perspectives map to reflect on the future development of the dominant societal perspective regarding the management of the River Meuse. The procedures for applying the perspectives mapping tool in the scenario analysis process are further described in the next section on the case study of the River Meuse.

\section{Case study of the River Meuse}

The extended perspectives approach has been applied in a case study on the management of the River Meuse in the Dutch Province of Limburg. This case study was focussed on two questions: in which way and under which circumstances did perspective shifts in water management in Limburg take place in history? And in which way and under which circumstances might perspective shifts take 


\begin{tabular}{|c|c|c|c|c|c|}
\hline & & HIE & EGA & IND & \\
\hline \multirow{5}{*}{ 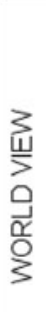 } & Value of water & Diversity of functions & Well-being & Welfare & back to main view \\
\hline & Water problem perception & Serious but manageable & Serious problem & No problem & \multirow{13}{*}{$\begin{array}{l}\text { Edit: Perspective: } \\
\odot 1800-1964 \\
\odot 1964 \text { - } 1990\end{array}$} \\
\hline & Trust in water technology & Positive but reserved & Distrust & Positive, great trust & \\
\hline & Expectation climate change & Average trend & High trend (worst case) & Low trend (best case) & \\
\hline & Socio- economic development & Average trends & Weak growth & Strong growth & \\
\hline \multirow{9}{*}{ 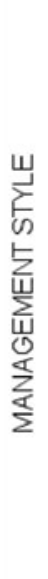 } & Water priorities & Conservation \& win- win & Compensation \& ecology & Innovation \& economy & \\
\hline & Flood management & Flood prevention & Avoid vulnerable areas & Adaptation \& innovation & \\
\hline & Water supply principle & Demand driven & Supply driven & Market driven & \\
\hline & Water system planning & Damming and regulation & Natural resilience & Opportunistic & \\
\hline & Spatial planning & Water follows & Water is guiding & Water offers opportunities & \\
\hline & Responsibility & National \& European govs & Regional govs \& NGOS & Private sector \& individuals & \\
\hline & Process design & Norms \& expert knowledge & Participatory decision making & Free market & \\
\hline & Identity and knowledge & Water authority NL & Catchment \& local scale & International companies & \\
\hline & Level of integrality & Sectoral & Integral & Competition & \\
\hline
\end{tabular}

Fig. 3 The perspectives map for Dutch river management. The perspectives map consists of a set of salient beliefs (the rows) regarding, for example, the value of water, trust in technological solutions, the priority given to water functions, the main principle of water management and spatial panning, and the way the water management process should be carried out. For each belief, the

place in the future? During these sessions, there was time to discuss what kind of policy relevant insights this would generate. The case study as such was less focussed on the realization of new substantive knowledge regarding the management of the River Meuse. The main focus was on methodological learning with regard to the added value of the extended perspectives scenario approach.

\section{Context}

The context of the case study was the River Meuse in the Netherlands. Along the Limburg Meuse, the river and its floodplains support a variety of societal functions, including housing, shipping, agriculture and horticulture, mineral extraction, and ecology. Despite these virtues of the Meuse, there is also reason for concern. Partly due to recent flood events in 1993 and 1995, and exceptionally dry summers in 2002 and 2003, there is a growing recognition that climate change, urbanization, and increasing water demands are increasing the vulnerability toward flooding and drought (Valkering 2009). The need for adaptation measures is broadly recognized in Dutch river management (e.g. see V\&W 2009). hierarchist, individualist, and egalitarian positions (columns) are given. The current map compares the historical dominant perspectives of 1800-1960 (yellow) and 1960-1990 (blue); yellow with a blue rim indicates an overlapping belief. See also "Perspective changes in the past" (color figure online)

In the Netherlands, river management is relatively decentralized (Enserink et al. 2003). The main responsible for the main surface water bodies_-like the River Meuse-is the national Ministry of Transport, Public works, and Water Management. However, through the close linkage with spatial planning, and given the ambition for stakeholder participation formulated at both European and national policy levels, river management may involve a variety of stakeholders, including regional governments (provinces, municipalities, water boards) and (associations of) boaters, farmers, nature conservationists, and citizens. Water management is thus often a collaborative task, in which a variety of stakeholder perspectives are taken into account.

Currently, there is an ongoing river management project along the Meuse- the 'Meuse works' - aiming to improve flood protection, nature development and shipping, through a river widening and natural river restoration approach. However, the problematic planning phase of this project of this project seems to indicate that the recognized shift in river management style (Van der Brugge et al. 2005)—i.e. from a dike-building toward a natural river restoration approach—is not yet a set course (Valkering 2009). Indeed, recent strategic policy documents (Deltacommissie 2008; 
V\&W 2009) take into consideration various alternative approaches, including flood resistent building and broadened dikes, reflecting diverging river management perspectives. That makes the future of the River Meuse interesting to explore.

\section{Process characteristics}

The case study involved a series of four facilitated workshops carried out over the course of 1 year. Participants included representatives of governments (both on the regional and on the national scale), organizations specialized in nature development, the shipping sector, the drinking water supply sector, and scientists. In total, 15 experts have been involved representing different perspectives and expertise with regard to water management. The 1st workshop was concerned with analyzing and explaining perspectives shifts in history. The 2 nd workshop focussed on identifying the current (dominant) perspective and undercurrents. Workshops 3 and 4 explored possible shifts in perspectives in the future, with an explicit focus on policy relevance in the final workshop. The results of the workshops were analyzed by the project team, and the group of experts reflected on these insights. In the following, we focus on the use of the perspectives mapping tool in the scenario analysis process. For a detailed account of the participatory process, see Valkering et al. (2008).

Perspective changes in the past

The 1st workshop (Offermans and Valkering 2007b) focussed on the question: what can be learned about the dynamics of perspective change by reflecting on the past? In small discussion groups ( $\sim 6$ people), participants were challenged to reflect upon the historical perspective changes regarding the management of the River Meuse, and the event and development that put those changes in motion. After the workshop, the project team used the perspectives map to analyze the results. First, the recorded historical perspective changes were interpreted on the perspectives map. Second, the interpreted perspective changes were linked to the recorded events and developments that were said to have set those changes in motion to obtain preliminary insight into the drivers of historical perspective change.

The perspectives map proved suitable to interpret historical perspective change. Three major shifts were identified: from a rather hierarchist-individualist period (1800-1960) of economic development and large-scale canalization works, to a more egalitarian period (1960-1990) with increasing priority for ecological values and water quality, to a return to hierarchist values (1990-2007) with increasing flood awareness and water level control, see Fig. 3. The analysis of the drivers allowed for testing the hypothesis that perspectives are resistant to change. Indeed, single events or developments appeared insufficient to drive a perspective change, although they can play important catalytic roles. Another insight was that perspective change seemed strongly driven by 'external' events and developments, such as an industrial accident upstream causing a sudden heavy pollution, increasing global environmental awareness, and climate change. Context changes thus seemed equally important drivers of perspective change, as the changes pertaining to the direct environment of the River Meuse.

\section{Perspectives in the present}

The 2nd workshop (Offermans and Valkering 2007a) zoomed in further on the current perspectives on the management of the River Meuse. Under the assumption that the workshop participants formed a fair representation of river management in the region, the mapping tool was used to characterize the dominant perspective and relevant undercurrents. On the basis of a previously completed questionnaire, small discussion groups were formed of 'like-minded' people adhering to a similar perspective. Following, the groups were challenged to convey their perspective through a discussion about their true priorities and ideals regarding the River Meuse, ignoring the current constraints as much as possible. In the ex-post analysis of the results on the perspectives map, the similarities between the two groups were assumed to be representative for the dominant perspective. The differences between both groups were assumed to reflect the undercurrents.

This analysis of group perspectives proved difficult. First, the participants' perspectives elicited from the previously completed questionnaire seemed rather inconsistent with the perspectives emerging out of the discussion groups. Second, the perspective difference between the discussion groups was much smaller than the project team expected. It appeared that the participants reasoned more from the viewpoint 'what is currently possible' rather than 'what should we ideally do'.

Nonetheless, the analysis framework allowed for insight into the perspective diversity among the workshop participants. In line with the assumption of heterogeneous perspectives, the dominant perspective appeared to consist of a mix of elements of the stereotypical perspectives. A predominantly hierarchist view (e.g. 'water follows', 'government responsibility', 'win-win solutions') was supplemented with individualist ('no problem', 'trust in technology') and egalitarian ('participatory decision-making', 'prioritising ecology') beliefs. Also, a number of crucial belief differences between the subgroups could be identified concerning the beliefs regarding water management 
Fig. 4 Perspective changes in the 'Limburg Cares' scenario, including potential bifurcations as a result of surprise

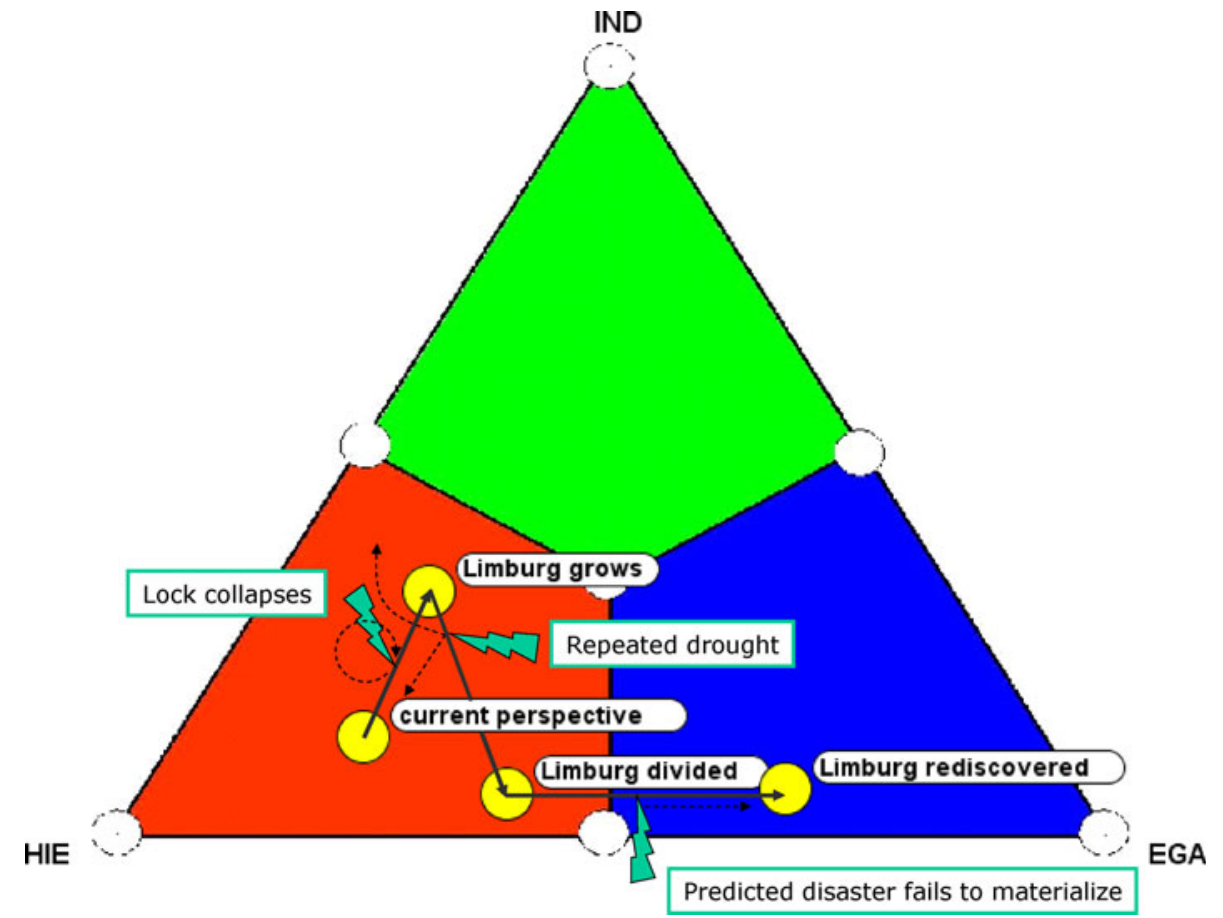

responsibility ('governments' vs. 'private sector and individuals'), water priority ('compensation and ecology' vs. 'innovation and economy'), and flood management ('flood prevention vs. 'adaptation and innovation'). For our analysis, these perspective differences were interpreted as hypothetical egalitarian and individualist undercurrents, countering the predominantly hierarchist dominant perspective (see Fig. 2).

Possible perspective changes in the future

In the 3rd and 4th workshops, perspective changes toward the future were explored. The 3rd workshop (Offermans and Valkering 2007d) aimed for a first exploration of future perspective change, notably to assess possible drivers of perspective discontinuities. The participants first engaged in a brainstorming session to reflect on the 'durability' of the current dominant perspective. Under what circumstances, events, and developments will the dominant perspective hold, and (conversely) when will it become unsustainable? In a second exercise, a selection of the mentioned factors was reasoned through, yielding a series of perspective change story-lines. The 4th workshop (Offermans and Valkering 2007c) aimed to derive more comprehensive narratives of perspective change. The participants (in two parallel groups) were confronted with two context scenarios, one showing rather linear context developments, the other describing discontinuous trends. ${ }^{6}$

\footnotetext{
6 The context scenarios were developed prior to the workshop, based on a previous regional scenario study.
}

The context scenarios also included a number of potentially surprising events (in the form of hypothetical newspaper headlines), mostly inspired by the drivers mentioned in the previous workshop (e.g. a dam break, an airplane disaster, or a persistent drought). The participants were guided through the scenarios and asked to reflect on the consequences of the envisioned developments and events for the dominant perspective on river management, using the developed perspectives map. ${ }^{7}$

The workshops resulted in a palette of possible drivers of perspectives changes, and eventually two scenarios of perspective change (Valkering et al. 2008). The so-called 'Limburg Cares' scenario is particularly interesting as it explores a trend break. The adopted context scenario initially develops along individualist lines (continuing economic growth, spatial pressure, privatization, new technologies, and innovative use of space), but curbs gradually in a more egalitarian direction (aging population, stagnating economic growth, receding government, focus on regional identity, and increasing dependency on social support from friends and relatives). Reasoning through the implication of this context scenario for the water management perspective, three phases appeared: 'Limburg grows', 'Limburg divided', and 'Limburg rediscovered', see Fig. 4. In the first phase, 'Limburg grows', incremental changes toward individualism were projected to occur (e.g. increasing individual responsibility, economic appreciation of minor risks), in line with the context developments offered. Eventually, the trend

\footnotetext{
7 The perspectives map was presented on paper, as the computer tool was not yet operational at that time.
} 
toward egalitarianism was projected to prevail ('Limburg rediscovered') with a focus on collective interests and sustainability, new regional and societal governing institutions, and successful cross-border collaboration.

This scenario serves to illustrate the type of insight that can be obtained:

- The effect of context developments on the dominant water management perspective, as perceived by the workshop participants, appears consistent with the hypothesis of surprise. For example, typical egalitarian confirmations drive the dominant perspective in an egalitarian perspective.

- Some beliefs, however, appear more persistent than others. Salient beliefs like 'problem perception' (serious but manageable) and notably 'responsibility' (government holds final responsibility) remained invariant under all scenario phases.

- During a transitional period, tensions may occur. In the transitional period ('Limburg divided'), some groups hold onto their individualist beliefs, strictly pursuing their self-interest to 'save their skin', while other groups shift to egalitarian beliefs, stressing solidarity to overcome the problems encountered. Also, while there is a clear tendency to avoid societal risks (like flood risk), the government lacks the financial means to exclude those risks effectively.
- The effect of surprising events can be counter-intuitive. The surprise 'repeated drought' in the 'Limburg divided' period, for example, tends to reflect a hierarchist and individualist surprise. The workshop participants, however, envisioned two possible responses, respectively toward hierarchism (strong government action to safeguard water supply) and individualism (maximizing individual water extraction causing (cross-border) water conflict)! The effect of a surprising event thus not only depends on the nature of the event itself, but also on the context under which it occurs.

Evaluating a strategic water management plan

In the second part of the 4th workshop (Offermans and Valkering 2007c), the participants were confronted with the perspective (as analyzed by the project team) underlying strategic national policy documents on water management and spatial planning. This so-called 'Dutch water vision' was compared to the perspective development portrayed in their scenarios using the perspectives map.

The comparison revealed various tensions regarding the various salient beliefs, see Fig. 5. For example, while the water vision calls for increased responsibility for private parties, the Limburg Cares scenario portrays a future in which citizen groups and NGOs at the regional level take

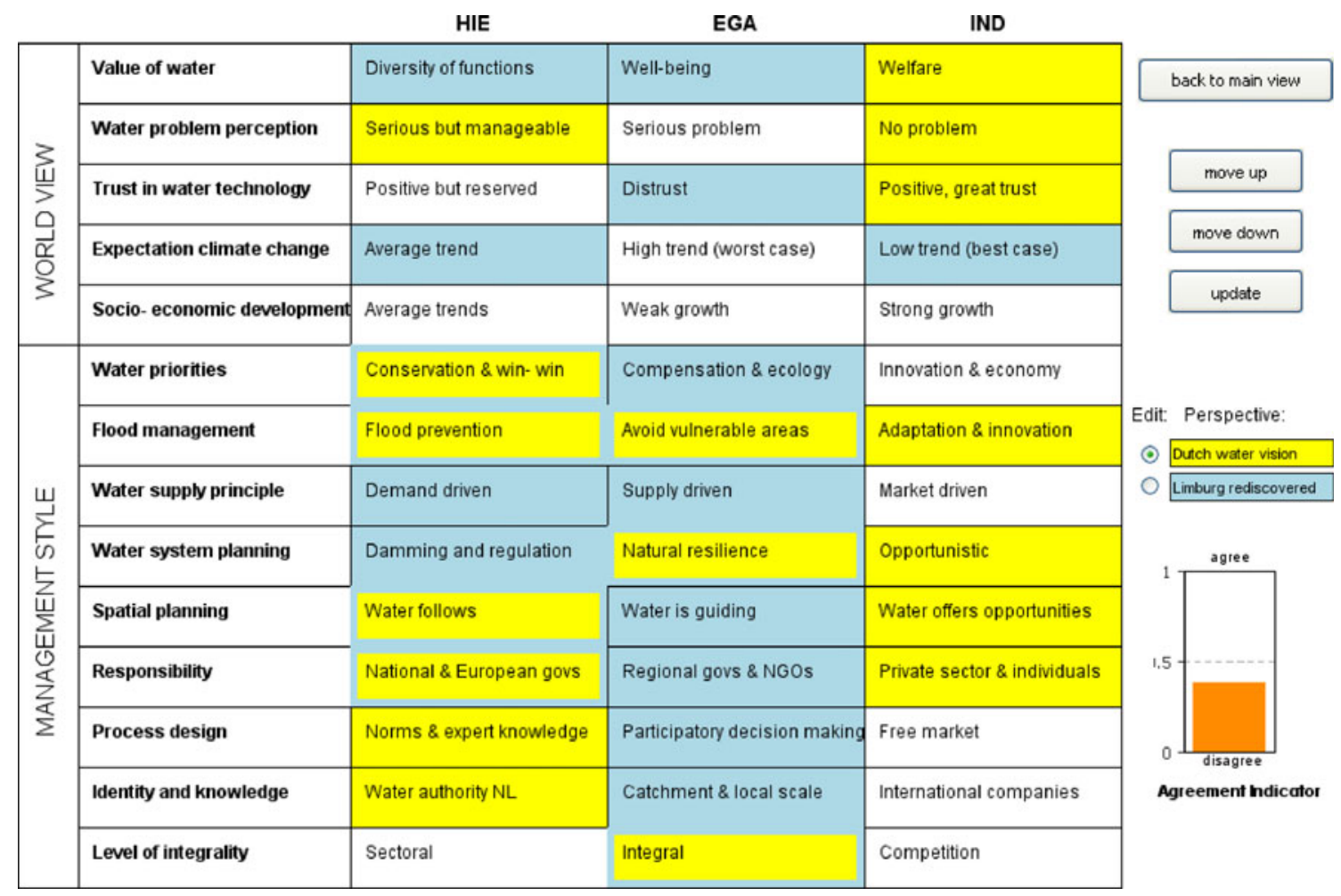

Fig. 5 The perspective underlying the 'Dutch water vision' (yellow) compared to the dominant societal perspective of Limburg rediscovered (Limburg Cares scenario, blue). Yellow with a blue rim implies that the beliefs overlap 
more initiative and responsibility. Exploring such tensions may help to be aware of the possibility that more regional and civil forms of government are called for.

Note, finally, that the various surprises included in the scenarios can increase or decrease the above tensions, depending on the direction of perspective change set in motion by the event. The event 'repeated drought' in the Limburg Cares scenario and the associated move toward hierarchism, for example, tends to increase tension. The increasing call for government responsibility conflicts with the ambition of more responsibility for private parties expressed in the Dutch water vision. This illustrates the importance of anticipating surprising events in strategic water management policy.

\section{Discussion and outlook}

In this section, we summarize and discuss our findings. We will do so by addressing the three research questions formulated in the introduction. The section is concluded with an outlook for further research.

Key insights into the scenario analysis of perspective change

- How to systematically include societal perspective dynamics in scenario analysis?

In this paper, we aimed to further develop the approach of perspective-based scenario analysis. To this end, we developed the concept of perspectives mapping, in which perspectives are quantified as 'positions', and perspective changes as 'pathways', on the perspectives map. The perspectives mapping approach was applied in a participatory scenario development process concerning the case study of River Meuse, in which eventually two prototype scenarios were developed, in which context changes, perspective changes, the role of surprising events, and policy implications are coherently described. In this process, perspectives mapping was applied to

- interpret historical perspective changes recorded during a workshop

- analyze the drivers of such historical perspective change

- classify the perspectives of workshop participants and analyze the diversity among them in terms of 'dominant perspectives' and 'undercurrents'

- support reflection on future perspective change as a result of surprising developments and events

- support comparing possible future societal perspectives with perspectives underlying strategic policy documents
As such, the mapping approach was useful, both as an analytical tool to support the analysis of perspective dynamics by the project team, and a participatory tool to support reflection on perspective dynamics by the workshop participants.

However, two critical issues were identified that require further attention in future work: First, the scenarios still describe insufficiently the complex action-reaction patterns underlying the development of context, societal perspectives, water management, and the water system. For instance, the scenarios properly illustrate how context changes drive perspective change, including (in the Limburg Cares scenario) a perspective-based trend break. However, the further implication for concrete water management strategies, their effects on the water system, and possible feedbacks to the societal perspective have not yet been reasoned through. Also, the future scenarios do not yet include the dynamics between dominant perspectives and undercurrents as postulated in "Analytical framework for describing and analysing societal perspective dynamics". In follow-up work, the scenarios should thus become richer in terms of representing water-society interactions and complex social dynamics.

Second, the insights into societal perspective dynamics obtained from workshops alone need to be interpreted with care. Even when participants are carefully selected, it remains questionable to what extent the perspective diversity elicited among workshop participants is representative for the actual perspective diversity in the river management society. The majority of participants in the case study, for example, seemed to reflect similar perspectives. Moreover, it appeared that they found it difficult to 'let go' of current constraints when discussing their water management ideals in the 2nd workshop. To further underpin the mapping of societal perspectives and perspective change, a broader social scientific analysis may be required, e.g. using historical analysis and survey techniques.

- To what extent does the extended perspectives approach provide insights into the drivers of perspective change?

Both the historical analysis and the future outlooks provided preliminary insight into the drivers of perspective change. In particular, it allowed for testing the formulated hypotheses that perspective change is driven by surprising events and developments as considered by the dominant societal perspective, but that societal perspectives are also resistant to change. Typical insights were that:

- societal perspectives on river management are subject to change

- single events or developments indeed appear insufficient to drive a perspective change, although they may play catalytic roles 
- perspective changes are often put in motion by external events and developments outside the sphere of influence of river management in Limburg

- some beliefs-for example regarding problem perception and the water management responsibility-appear relatively persistent to change

- the effect of a surprising event not only depends on the nature of the event itself, but also on the context in which it occurs.

Particularly intriguing was that the assumption that solely the nature of a surprising event determines the direction of perspective change seems insufficiently nuanced. In some examples, events that a priori seemed a surprise for a specific perspective were actually enforcing that perspective (rather than weakening it) due to mitigating circumstances. Hence, the context within which an event occurs is thus considered highly important for understanding its effect. These, and other, preliminary insights are considered a basis for formulating more detailed hypotheses on the drivers of perspective change, which may be explored in future research.

Finally, although we observed a rather consistent relation between the context developments and perspective change, it was not very critically assessed. In reality, institutional settings, power structures and existing infrastructures slow down, or even block societal change (Rotmans 2005; Van der Brugge 2009). Exploring such potential blockades to perspective change in the scenario development process may improve the plausibility of the outlooks of perspective change.

- What is the potential contribution of the extended perspectives approach for supporting water management policy and societal learning?

In a concluding discussion, the 4th workshop was evaluated and general policy insights were drawn (Offermans and Valkering 2007c). Three main features were highlighted:

On a general note, the scenario development process was said to contribute to creating awareness about the plurality of perspectives and the dynamics of perspective change. The participants found the approach useful for understanding the ongoing social 'struggle' between fundamentally different views on water management, which were considered "perhaps even more important than the physical reality". Also, including dynamics of perspective change in the scenarios provided a powerful tool to illustrate that dominant ways of thinking about water management are always subject to change, and that the current way of thinking might not be the most adequate to manage future situations. "Think future oriented" was a general key message that reflected those ideas.
Monitoring societal perspectives was considered to be one of the main potentials of this approach for policy support. Participants argued that the perspective underlying strategic water management policy should be more explicitly addressed and compared with societal views. Moreover, water management policy needs to be flexible to be able to anticipate changing societal views. Finally, possible perspective differences between the national and local scale levels could be monitored, to support consistency between top-down visions and bottom-up initiatives.

Finally, the participants learned that the timing of water management policy is important. Shocking events-such as flood-related disasters, drought or water quality calamities-can have a significant impact on the societal perspective, and hence on the societal support for water management policy. The perspectives approach could be adopted to explore the consequences of shocking events for water management policy, to consider beforehand which policy responses might be most suitable in the case such an event would take place.

\section{Outlook}

The approach so far has focussed on mapping the development of perspectives over time, understanding the drivers of perspective change, and reasoning through the implications for water management policy. Insights into those dynamics were obtained through a participatory process with stakeholders. For the approach to mature, main challenges were said to include a better representation of the interactions between the water system and society, a better representation of the social dynamics of perspective change, and a better underpinning of the insights into societal perspective dynamics emerging from the participatory process.

We therefore envision a three-pillar approach to our future investigation of perspectives and perspective change. The first pillar is the development of a sound theoretical framework for understanding the dynamics of societal perspective change, and notably the interaction between water system changes and societal responses. To this end, insight from cultural theory (Thompson et al. 1990), Advocacy Coalition Framework theory (Sabatier and Jenkins-Smith 1993), transitions theory (Rotmans 2005; Van der Brugge 2009), and Integrated Assessment Modeling (i.e. the conceptual model of Pressure State Impact Response) is adopted for developing a theoretical framework tailored to our case (see also Valkering et al. 2009).

The second pillar is empirical data gathering. To this end, the methodology for measuring societal perspectives 
will be further developed and applied to analyze a number of historical cases of perspective change (e.g. through literature research and interviews) and a better assessment of the current status quo (e.g. through surveys). This will improve the understanding of the drivers of perspective change-and possibly the dynamics between dominant perspectives and undercurrents though which perspective change emerged-for different water management case studies in different contexts.

The third pillar is participatory simulation through multiple-perspective based games. Multiple-perspective based gaming - previously described in Valkering et al. (2009) —entails setting up a policy-gaming environment in which players advocating different perspectives compete over water management policy. The game allows for the formation of coalitions representing dominant perspectives and undercurrents. A crucial feature of the gaming approach is an integrated assessment meta model (Haasnoot et al. 2009) that allows for rapid simulation of water related impacts. Operating this model in the gaming environment allows for investigating the interaction between the water system and the (artificial) water management society in a highly interactive way. The observed game dynamics between the dominant perspective and undercurrent coalitions is assumed to generate insight into the dynamics of perspective change. Eventually, insight into the game dynamics may be translated into generic 'response rules' reflecting societal perspective changes in response to given events and developments. This would allow running and analyzing statistical ensembles of perspective change trajectories, which would further enhance insights into future perspective change (see also Haasnoot et al. 2009).

The three methodological approaches together are assumed to provide adequate insights for developing coherent narratives-combining qualitative and quantitative elements-describing future trajectories of perspective change.

\section{Conclusion}

In this paper, we have aimed to further scenario methodology to explore future developments of societal perspectives on climate adaptation issues in a systematic way. To this end, the existing approach of perspective-based scenario analysis was extended with a perspectives mapping tool, which was applied and tested for the case study of the River Meuse. Overall, the results of this case study illustrate that the future development of societal perspectives is indeed relevant to consider. The development is uncertain, as it is influenced by various events and development in unpredictable ways. Also, this development is important, since it significantly influences the desirability of, and societal support for climate adaptation policy. Hence, it is a relevant factor to consider in the assessment of long-term river management strategies.

The case study also illustrates the potential of the approach to assess the dynamics of perspective change. We saw that perspective changes are not simply due to single events, but rather due to a combination of gradual developments and catalytic shock events, often external. The timing of the event therein was crucial, that is to say, if a certain event occurs, the response depends on the 'state' of the societal system at that time. This suggests that the susceptibility of societal systems to large perspective shifts is variable and evolves over time. These, and other, preliminary insights are considered a basis for formulating more detailed hypotheses on the drivers of perspective change, which may be explored in future research.

The scenario analysis of perspective change appears promising for supporting climate adaptation policy. It may contribute to societal awareness about perspectives and perspective change and offers potential for monitoring societal perspectives, and evaluating the timing of water management policy in relation to the possible occurrence of surprising events. Moreover, it may offer a method for assessing the flexibility of water management strategies, by including the societal costs of a change of management style into the policy assessment. Finally, perspective changes are often considered necessary as part of sustainability transitions (e.g. Rotmans 2005; Tàbara and Pahl-Wostl 2007). In this light, exploring perspective change scenarios may offer support for policy makers (and other stakeholders) to proactively engage in such a transition processes (see also Sondeijker 2009).

Many challenges exist for further developing this approach into a mature scenario method for policy support. These challenges can be summarized as (a) a better integration of water knowledge in the scenario development process through the development and application of integrated water system models, (b) a better grounding of the perspective change model through further empirical research on additional case studies, (c) a better representation of the social dynamics of perspective change, and (d) analyzing possible future co-evolutionary trajectories of the coupled water-society system through a gaming simulation approach in the context of participatory scenario development.

Acknowledgments This research was funded by the Dutch 'Living with Water' program (Project P1015) and benefits from the follow-up project Perspectives in Integrated Water Resource Management in River Deltas. We would like to thank all workshop participants for their valuable contributions. 
Open Access This article is distributed under the terms of the Creative Commons Attribution Noncommercial License which permits any noncommercial use, distribution, and reproduction in any medium, provided the original author(s) and source are credited.

\section{References}

Bishop P, Hines A, Collins T (2007) The current state of scenario development: an overview of techniques. Foresight 9(1):5-25

De Vries BJM (2001) Perceptions and risks in the search for a sustainable world: a model-based approach. Int J Sustain Dev 4(4):434-453

Deltacommissie (2008) Samen werken met water. Bevindingen van de deltacommissie 2008. Staatscommissie voor Duurzame Kustontwikkeling. The Hague, The Netherlands

Enserink B, Kamps D, Mosterd E (2003) Public participation in river basin management in the Netherlands. The HarmoniCOP project-workpackage 4-case study of the Netherlands, Osnabrück, Germany

Haasnoot M, Middelkoop H, Van Beek E, Van Deursen WPA (2009) A method to develop sustainable water management strategies for an uncertain future. Sustain Dev. doi:10.1002/sd.438

Hoekstra AY (1998) Perspectives on water: an integrated modelbased exploration of the future. International Books, Utrecht, The Netherlands

Hulme M, Neufeldt H, Ritchie A (eds) (2009) Adaptation and mitigation strategies: supporting european climate policy. The final report from the adam project. Tyndall Centre for Climate Change Research, University of East Anglia, Norwich, UK

IPCC (2007) Climate change 2007: synthesis report. Contribution of working groups $\mathrm{i}$, ii and iii to the fourth assessment report of the intergovernmental panel on climate change. IPCC, Geneva, Switzerland

Kok K, Rothman D, Patel M (2006) Multi-scale narratives from an ia perspective: part i. European and mediterranean scenario development. Futures 38:261-284

Middelkoop H, Van Asselt MBA, Klooster SAVT, Deursen WPAV, Kwadijk JCJ, Buiteveld H (2004) Perspectives on flood management in the rhine and meuse rivers. River Res Appl 20:327-342

Offermans AGE, Valkering P (2007a) Leren van het heden. De maas in huidig perspectief (workshopverslag). ICIS, Maastricht, The Netherlands

Offermans AGE, Valkering P (2007b) Leren van het verleden. De maas in historisch perspectief (workshopverslag). ICIS, Maastricht, The Netherlands

Offermans AGE, Valkering P (2007c) Ontmoet de toekomst. Scenario's voor perspectiefverandering in het waterbeheer en lessen voor beleid (workshopverslag). ICIS, Maastricht, The Netherlands

Offermans AGE, Valkering P (2007d) Waterbeheer in een veranderende omgeving. Op zoek naar perspectiefverschuiving (workshopverslag). ICIS, Maastricht, The Netherlands

Offermans A, Haasnoot M, Valkering P (2009) A method to explore social response for sustainable water management strategies under changing conditions. Sustain Dev. doi:10.1002/sd.439

Richardson K, Steffen W, Schellnhuber HJ, Alcamo J, Barker T, Kammen DM, Leemans R, Liverman D, Munasinghe M, OsmanElasha B, Stern N, Waever O (2009) Synthesis report from: climate change, global risks, challenges, \& decisions. Copenhagen, 10-12 Mar 2009

Rothman D (2006) Scenarios: structured thinking about the future. In: Valkering P, Amelung B, Van der Brugge R, Rotmans J (eds)
More puzzle-solving for policy: integrated assessment from theory to practice. ICIS, Maastricht, The Netherlands

Rotmans J (2005) Societal innovation: between dream and reality lies complexity. DRIFT: Erasmus University Rotterdam, Rotterdam

Rotmans J, de Vries HJM (eds) (1997) Perspectives on global change: the targets approach. Cambridge University Press, Cambridge, UK

Sabatier PA, Jenkins-Smith HC (1993) Policy change and learning: an advocacy coalition approach. Theoretical lenses on public policy. Westview Press, Boulder, USA

Sondeijker S (2009) Imaging sustainability. Erasmus University Rotterdam, Rotterdam, The Netherlands

Swart RJ, Raskin P, Robinson J (2004) The problem of the future: sustainability science and scenario analysis. Glob Environ Change 14:137-146

Tàbara JD, Pahl-Wostl C (2007) Sustainability learning in natural resource use and management. Ecol Soc 12(2):3

Thompson M, Ellis R, Wildavsky AB (1990) Cultural theory. Political cultures. Westview Press, Boulder, USA

V\&W (2009) Nationaal waterplan. Ministry of transport. Public Works and Water Management, The Hague, The Netherlands

Valkering P (2009) Toddling 'long the river meuse: integrated assessment and agent-based modelling to support river management. Maastricht University, Maastricht, The Netherlands

Valkering P, Offermans A, Lieshout MV, Rijkens N, Brugge RVD, Haasnoot M, Middelkoop H, Deursen WV, Beersma J, Buiteveld $\mathrm{H}$ (2008) Inspelen op verandering: naar een robuuste en flexibele strategie voor waterbeheer. Eindrapportage perspectieven in integraal waterbeheer. ICIS, Maastricht

Valkering P, Tàbara JD, Wallman P, Offermans A (2009) Modelling cultural and behavioural change in water management: an integrated, agent based, gaming approach. Integr Assess J 9(1):19-46

Van't Klooster SA, Van Asselt MBA (2006) Practising the scenarioaxis technique. Futures 38:15-30

Van Asselt MBA (2000) Perspectives on uncertainty and risk: the prima approach to decision support. Kluwer, Dordrecht, The Netherlands

Van Asselt MBA, Rotmans J (1996) Uncertainty in perspective. Glob Environ Change 6(2):121-157

Van Asselt MBA, Middelkoop H, Van't Klooster SA, Van Deursen WPA, Haasnoot M, Kwadijk JCJ, Buiteveld H, Können GP, Rotmans J, Van Gemert N, Valkering P (2001) Development of flood management strategies for the rhine and meuse basins in the context of integrated river management. Report of the irmasponge project 3/nl/1/164/991518301. ICIS, Maastricht/Utrecht, The Netherlands

Van Asselt MBA, Rotmans J, Rothman DS (eds) (2005) Scenario innovation. Experiences from a european experimental garden. Taylor \& Francis, London, UK

Van de Kerkhof M, Hisschemoller M, Spanjersberg M (2002) Shaping diversity in participatory foresight studies. Green Manag Int 37(1):85-99

Van der Brugge R (2009) Transition dynamics in social-ecological systems. The case of dutch water management. Erasmus University, Rotterdam, The Netherlands

Van der Brugge R, Rotmans J, Loorbach D (2005) The transition in dutch water management. Reg Environ Change 5:164-176

Van Notten P (2005) Writing on the wall: scenario development in times of discontinuity. Maastricht University, Maastricht, The Netherlands

Verweij M, Thompson M (eds) (2006) Clumsy solutions for a complex world. Governance, politics and plural perceptions. Global issues series. Palgrave Macmillan, New York, USA 